\title{
Severe anaemia is not associated with HIV-I env gene characteristics in Malawian children
}

\author{
Job CJ Calis*1,2, Hellen P Rotteveel ${ }^{3}$, Antoinette C van der Kuyl ${ }^{3}$, \\ Fokla Zorgdrager ${ }^{3}$, David Kachala ${ }^{2}$, Michaël Boele van Hensbroek ${ }^{1,2,4}$ and \\ Marion Cornelissen ${ }^{3}$
}

\begin{abstract}
Address: ${ }^{1}$ Emma Children's Hospital, Academic Medical Centre, Amsterdam, The Netherlands, ${ }^{2}$ Malawi-Liverpool-Wellcome Trust Clinical Research Programme, College of Medicine, Blantyre, Malawi, ${ }^{3}$ Laboratory of Experimental Virology, Department of Medical Microbiology, Centre for Infection and Immunity Amsterdam (CINIMA), Academic Medical Centre of the University of Amsterdam, Amsterdam, The Netherlands and ${ }^{4}$ Liverpool School of Tropical Medicine, Liverpool, UK

Email: Job CJ Calis* - Job.Calis@gmail.com; Hellen P Rotteveel - Hellen.Rotteveel@student.uva.nl; Antoinette C van der Kuyl - a.c.vanderkuyl@amc.uva.nl; Fokla Zorgdrager - f.zorgdrager@amc.uva.nl; David Kachala - dkachala@mlw.medcol.mw; Michaël Boele van Hensbroek - mbvh04@gmail.com; Marion Cornelissen - m.i.cornelissen@amc.uva.nl

* Corresponding author
\end{abstract}

Published: 29 February 2008

BMC Infectious Diseases 2008, 8:26 doi:10.1 I86/147/-2334-8-26
Received: 24 May 2007

Accepted: 29 February 2008

This article is available from: http://www.biomedcentral.com/I47I-2334/8/26

(c) 2008 Calis et al; licensee BioMed Central Ltd.

This is an Open Access article distributed under the terms of the Creative Commons Attribution License (http://creativecommons.org/licenses/by/2.0), which permits unrestricted use, distribution, and reproduction in any medium, provided the original work is properly cited.

\begin{abstract}
Background: Anaemia is the most common haematological complication of HIV and associated with a high morbidity and a poor prognosis. The pathogenesis of HIV-associated anaemia is poorly understood and may include a direct effect of HIV on erythropoiesis. In vitro studies have suggested that specific HIV strains, like X4 that uses the CXCR4 coreceptor present on erythroid precursors, are associated with diminished erythropoiesis. This co-receptor affinity is determined by changes in the hypervariable loop of the HIV-I envelope genome. In a previous case-control study we observed an association between HIV and severe anaemia in Malawian children that could not be fully explained by secondary infections and micronutrient deficiencies alone. We therefore explored the possibility that alterations in the VI-V2-V3 fragment of HIV-I were associated with severe anaemia.
\end{abstract}

Methods: Using peripheral blood nucleic acid isolates of HIV-infected children identified in the previous studied we assessed if variability of the VI-V2-V3 region of HIV and the occurrence of X4 strains were more common in HIVinfected children with (cases, $n=29$ ) and without severe anaemia (controls, $n=30$ ). For 15 cases bone marrow isolates were available to compare against peripheral blood. All children were followed for 18 months after recruitment.

Results: Phylogenetic analysis showed that HIV-I subtype $C$ was present in all but one child. All VI-V2-V3 characteristics tested: V3 charge, VI-V2 length and potential glycosylation sites, were not found to be different between cases and controls. Using a computer model (C-PSSM) four children (7.8\%) were identified to have an X4 strain. This prevalence was not different between study groups $(p=1.00)$. The $V 3$ loop characteristics for bone marrow and peripheral blood isolates in the case group were identical. None of the children identified as having an X4 strain developed a (new) episode of severe anaemia during follow up.

Conclusion: The prevalence of $\mathrm{X} 4$ strains in these young HIV-I-subtype-C-infected children that were most likely vertically infected and naïve to anti-retroviral therapy can be considered high compared to previous results from Malawi. It is unlikely that VI-V2-V3 fragment characteristics and HIV co-receptor affinity is an important feature in the development of severe anaemia in Malawian children. 


\section{Background}

Anaemia is the most common haematological complication of HIV in adults and children worldwide [1-3] and is associated with a reduced quality of life and a high morbidity [4]. Inadequate erythropoiesis is generally considered to be the main pathophysiological mechanism of HIV-associated anaemia $[1,5,6]$. Despite the obvious medical importance of anaemia the aetiology of this erythropoietic failure is still not well understood. Several possible pathways have been investigated including opportunistic infections, micronutrient deficiencies and the more recently identified direct effect of HIV on erythropoiesis $[3,7]$. The induction of anaemia by specific strains of HIV is an example of this direct of effect of HIV [8].

Early in infection the HIV-1 population usually consist of a strain that has the capacity to bind to both CD4 and the co-receptor CCR5 (R5 strain)[9,10]. Later in infection a broadening or switch occurs and HIV evolves to infect cells expressing CD4 and the co-receptor CXCR4 (R4 strains) $[10,11]$. This switch is thought to occur in $50 \%$ of infections and is associated with an accelerated loss of CD4+ T-cells and progression to AIDS [12].

Like the T-helper cells, erythropoietic stem cells express both CD4 and CXCR4 on their membrane[13,14]. Although productive infection is uncommon in erythroid precursor cells [3], several in vitro studies have associated X4 strains with cell death in erythroid and other cell lines [7,15-17]. Another similarity between T-helper cells and erythroid cells is the decline in both cell types during disease progression [3,7]. Large studies have suggested that anaemia might even be a better predictor of mortality than loss of CD4 cells or HIV load increase [5,18,19]. A decline of $1 \mathrm{~g} / \mathrm{dL}$ in the haemoglobin concentration was associated with a greater increased hazard of death than a halving of the absolute CD4 count or a log increase in viral load [18]. The reversal of anaemia, again similar to an increase in T-helper cells, was associated with a better life expectancy $[18,19]$. Despite these similarities to $\mathrm{T}$ cells, no study has evaluated if the decrease in erythrocytes might be a direct or indirect consequence of an alternated co-receptor affinity [16].

Co-receptor affinity is a consequence of changes in the variable loops (V1-V2-V3) of the envelope protein (env) of HIV-1. Especially a high V3 amino acid charge was found to be associated to X4 co-receptor affinity [20-24] and several models have been published to predict co-receptor affinity using V3 data [25-28]. Changes to the V1-V2 fragment appear to be more indirectly linked to X4 affinity and are increasingly associated with a neutralizing antibody escape [29-37]. These changes include an increased number of potential N-linked glycosylation sites in V1-V3
[30-35] and possibly an extended length of the (V1-)V2 fragment [29,36,37].

In a recent case-control study we found a strong association between HIV and severe anaemia in African children [38]. This association could partly be explained by opportunistic infections with micronutrient deficiencies playing only a modest role. After correction for this an independent association remained which can be explained by a direct effect of HIV on erythropoiesis. We hypothesized that the occurrence of X4 strains and other alterations of the hypervariable loops V1-V2-V3 of the HIV-1 env genome would be associated with severe anaemia. Using nucleic acid isolates of HIV-infected children with (cases) and without (controls) severe anaemia we assessed the prevalence of: (1) high V3 and total V1-V2-V3 amino acid charge; (2) an extended V1-V2 length; (3) an increase of potential N-linked glycosylation sites of the V1-V3 and V3 fragments; (4) a HIV-1 subtype C position specific scoring matrix (C-PSSM) that predicts co-receptor usage[25].

\section{Methods}

In two hospitals in southern Malawi we recruited two groups of children aged 6-60 months into a case-control study on severe anaemia (Haemoglobin concentration $<5$ $\mathrm{g} / \mathrm{dL}$ ) as previously described [38]. In short, a severely anaemic child requiring a blood transfusion (Case, Haemoglobin concentration $<5 \mathrm{~g} / \mathrm{dL}$ ) was recruited at presentation to hospital alongside two controls (Haemoglobin concentration $\geq 5 \mathrm{~g} / \mathrm{dL}$ ). One control was recruited from apparently healthy residents living within proximity of the case-patient (Community Control, CC) the other randomly selected at the outpatient department (Hospital Control, HC). On enrolment, a standardized study questionnaire and physical examination were completed, and blood samples were collected. In cases only, a bone marrow aspiration was performed under anaesthesia if the clinical condition permitted. Nutritional Z-scores were calculated in EPI info 2000 [39]. 'Wasting' (weight-forheight), applied to children with Z-scores <-2. Children requiring admission were treated in a study ward. All conditions were managed according to standard protocols. All three study groups (cases, HC and CC) were actively followed at 1, 3, 6, 12 and 18 months. In addition, children were passively followed by asking guardians to return to study clinics whenever the child was sick. During follow-up visits clinical data was collected and a peripheral blood haemoglobin concentration was determined. Fully informed consent was obtained from a parent or guardian in all three study groups. HIV testing was discussed after transfusion for the cases and on a follow-up visit for controls. The study was approved by the ethics committees of the College of Medicine, Malawi, and the Liverpool School of Tropical Medicine, UK. 


\section{Laboratory tests on site}

Haemoglobin was measured on site using a Hemocue system (Angelholm, Sweden). A full blood and reticulocyte count was performed by Coulter counter (Coulter, Hialeah, Fla).

C-reactive protein (CRP) was analyzed in heparin plasma on a Roche p800/p170 system (Roche, Switzerland). HIV testing was performed using two rapid tests (Determine, Abbott-Laboratories, Japan; Unigold, Trinity-Biotech, Ireland). Reactive results in children less than 18 months and discordant outcomes were resolved by PCR. Lymphocyte subsets including CD4 cell counts were measured, during the second year of recruitment, by adding 50 $\mu \mathrm{l}$ of whole blood to TRUECOUNT absolute count tubes (Becton Dickinson, USA) and incubated with $20 \mu \mathrm{l} \mathrm{Mul-}$ tiTest reagent. After incubation and red cell lysis, the cells were analysed on a Becton Dickinson FACSCalibur flow cytometer and analysed using MultiSet software (Becton Dickinson, USA). CD4 expressing T-cells were expressed as percentage of the total lymphocyte population and age adjusted cut-offs were used to define immunodeficiency[40]. Peripheral blood samples were separated and aliquots of serum and plasma were stored at -80C for later testing.

\section{DNA extraction and polymerase chain reaction (PCR)}

DNA was isolated from the blood and bone marrow samples with a silica-guanidiniumthiocyanate based method[41]. The target DNA (env gene) was amplified using polymerase chain reaction (PCR) with a pair of target-specific sense and antisense primers (Figure 1) in a 96well 9700 thermocycler (Applied Biosystems, USA). First a reverse transcriptase (RT)-PCR was performed using 10 $\mu \mathrm{l}$ of the eluated nucleic acid solution and Avian Myeloblastosis Virus reverse transcriptase (AMV-RT, Boehringer Mannheim) to generate cDNA. Five microliter of the PCR product was used with Amplitaq (Applied Biosystems, USA) to amplify the V1-V2-V3 env (810 bp) gene fragment, or in case this failed a combination of nested PCRs was performed to amplify this region as fragments (primers Figure 1).

\section{Sequencing and cloning}

PCR products were directly sequenced with the ABI Prism Big-dye Terminator v 1.1 Cycle Sequencing Kit in an ABI Prism 377 DNA sequencer using multiple fluorescent dyes (Applied Biosystems, USA). PCR fragments showing evidence of recombinants or a dual infection were cloned with TA TOPO cloning kit (Invitrogen, USA). For each sample at least eight clones were sequenced and from these a consensus sequence was made. All sequences were manually analysed and assembled with CodonCode Aligner (version 1.5.2.). Multiple sequences were aligned with CLUSTAL W [42] and optimised manually with BioEdit Sequence Alignment Editor (version 7.0.1).

\section{Viral Load determination}

The HIV-1 viral load in plasma was determined with an in-house real-time PCR assay, with primers located in the HIV-1 pol gene. Primer/probe sequences were: upstream primer 5'TGC ATT YAC CATACC TAG T 3', downstream primer 5'ATT GCT GGT GAT CCT TTC CA 3', and probe 5'AAA CAA TGA GAC ACC AGG GAT TAG ATA 3'. The probe was 6-FAM labelled. The detection limit of this assay was $5 \mathrm{HIV}-1$ RNA copies per reaction.

\section{Phylogenetic analysis}

Genetic subtypes were determined by phylogenetic analysis. The env gene sequence fragments were aligned with the corresponding reference sequences obtained from the Los Alamos HIV sequence database [43]. Phylogenetic reconstruction was carried out with Molecular Evolutionary Genetics Analysis (MEGA) software version 3.0. A model based upon the Kimura two-parameter model with pair wise deletion was used. Bootstrap values were based on a generation of 1000 replicate trees. Newly found recombinant forms were analysed using Simplot (version 3.5.1.0.) comparing recombinant sequences against a background of reference sequences.

\section{Potential N-linked glycosylation sites and Amino acid charges}

All protein fragments containing Asparagine $(\mathrm{N})$ and Serine $(\mathrm{S})$ or Threonine $(\mathrm{T})$ that were separated by any third amino acid $(\mathrm{X})$ other than Proline $(\mathrm{P})$ were counted as a glycosylation site (N-X-S/T) [44]. All possible glycosylation sites and the amino acid charges were counted for the V3 and V1-V2-V3 fragment separately.

\section{Subtype C-specific phenotype predictor (C-PSSM)}

A C-PSSM predictor is available online [45]. This predictor is based on the computational techniques presented in the paper from Jensen and colleagues [25].

\section{Statistics}

We compared characteristics of HIV-infected cases to HIVinfected controls using the Fisher exact and Chi-square test (categorical data) and the t-test or Wilcoxon rank sum test (continuous data). For $2 \times \mathrm{N}$ contingency tables the Fisher-Freeman-Halton exact test was used. For all tests a two-sided alpha of $<0.05$ was used to assess significance. The tested sample size would be able to detect an odds ratio of 8 or more assuming an X4 strain prevalence of $8 \%$ in the control population, a power of $80 \%$ and an alpha of 0.05. Analyses were performed using SPSS 12.0 (SPSS inc, USA) and StatsDirect 2.6 (StatsDirect ltd, UK). 


\begin{tabular}{|c|c|c|}
\hline \multicolumn{3}{|c|}{ Primers used to amplify V1-V2-V3 } \\
\hline \multirow{2}{*}{\multicolumn{3}{|c|}{\begin{tabular}{l|l} 
V1 V2 \\
Primer
\end{tabular}}} \\
\hline & & \\
\hline \multicolumn{3}{|l|}{ V1V2 primers } \\
\hline$* 5 ’ \mathrm{~V} 1 \mathrm{~V} 2-1$ & A0383 & TGT GTA CCC ACA GAC CCC AAC CC \\
\hline$* 5$ 'V1V2-2-SP6 & A0384 & ATT TAG GTG ACA CTA TAG \\
\hline *3’V1V2-3-T7 & A0387 & TAA TAC GAC TCA TAG GG \\
\hline *3’V1V2-4 & A0389 & ATT CCA TGT GTA CAT TGT ACT G \\
\hline \multicolumn{3}{|l|}{ V3 primers } \\
\hline *5'non BV3 in & A2603 & AAT GTC AGC ACA GTA CAA TG \\
\hline$* 5$ 'non BV3 out & A2602 & CCA GTG GTA TCA ACT CAA \\
\hline$* 3$ ' non BV3 in & A2604 & AT TTC TAA GTC CCC TCC TGA \\
\hline *3' non BV3 out & A2605 & TCT CCT CCT CCA GGY CTG AA \\
\hline \multicolumn{3}{|l|}{ V1V2V3 primers } \\
\hline *5'V1V2-1 & A0383 & TGT GTA CCC ACA GAC CCC AAC CC \\
\hline$* 5 ’ \mathrm{~V} 1 \mathrm{~V} 2-2$ & A0385 & GAG GAT ATA ATC AGT TTA TGG GA \\
\hline$* 3 ’ \mathrm{~V} 3$ & A2604 & AT TTC TAA GTC CCC TCC TGA \\
\hline *3'V3 & A2605 & TCT CCT CCT CCA GGY CTG AA \\
\hline \multicolumn{3}{|l|}{ Overlap V1V2V3 } \\
\hline$* 5^{\prime} \mathrm{V} 1 \mathrm{~V} 2-12$ & A3047 & AAT TGC TCT TTC AAT GCA ACC ACA GA \\
\hline$* 3 ' \mathrm{~V} 3-13$ & A3048 & AGA ATG YTT GTC CTG GTC CTA T \\
\hline
\end{tabular}

Figure I

PCR Primers used to amplify VI-V2-V3 fragment. A display of the primer sequences used to amplify the VI-V3 fragment located on the viral genome of the HIV-I env protein. External PCR: primers indicated with a blue *. Internal PCR primers are indicated with a red $*$ for the $V$ regions and with a green * for the $C$ regions.

\section{Results}

\section{Patient Characteristics}

The current study was embedded into a larger case-control study that followed children for an additional 18 months. That study recruited 381 children with severe and 757 children without severe anaemia over a two year period. Overall 1039 (91\%) parents consented to HIV testing, 57 $(5.0 \%)$ refused and $42(3.7 \%)$ were lost to follow up before counselling. Of all children tested 45 (13\%) of severely anaemic cases and $41(6 \%)$ non-severely anaemic controls were HIV-infected ( $\mathrm{p}<0.001)$. These 86 children formed the current study population and their baseline characteristics are described in Tables 1 and 2. Haemoglobin levels were lower in cases than controls but reticulocyte counts were not different between the study groups $(\mathrm{p}=0.72)$. Of all HIV-infected children, cases were more

Table I: Characteristics of the HIV-infected children per study group.

\begin{tabular}{lccc}
\hline & Cases & Controls & P \\
\hline HIV-infected & 45 & 41 & $\mathrm{n} / \mathrm{a}$ \\
Age (mean in months \pm SD) & $25.5 \pm 14.1$ & $28.8 \pm 12.4$ & 0.25 \\
Sex (M:F) & $18: 27$ & $23: 18$ & 0.14 \\
Haemoglobin (mean in g/dL \pm SD) & $3.6 \pm 0.7$ & $9.3 \pm 2.0$ & $\mathrm{n} / \mathrm{a}$ \\
Reticulocytes (Median and IQR *10e9/L) & $58.6(30.3-93.1) \mathrm{n}=35$ & $55.7(34.7-86.0) \mathrm{n}=31$ & 0.72 \\
CRP>I0 mg/L & $38 / 42(90 \%)$ & $25 / 36(69 \%)$ & 0.02 \\
\hline
\end{tabular}

Baseline characteristics of children with severe anaemia (cases, $\mathrm{Hb}<5.0 \mathrm{~g} / \mathrm{dL}$ ) as compared to those without severe anaemia (controls). SD: Standard deviation; IQR Inter Quartile Range; The number of children is only displayed if data was not available for all children. 
Table 2: Markers of disease progression and outcome study group.

\begin{tabular}{|c|c|c|c|}
\hline & Cases & Controls & $\mathbf{p}$ \\
\hline Wasting (Z-score weight for height <-2) & $7 / 36(19 \%)$ & $5 / 38(13 \%)$ & 0.46 \\
\hline Previous hospital admission & $25 / 44(57 \%)$ & $16 / 4 \mid(39 \%)$ & 0.10 \\
\hline Mortality (18 months) & $27 / 45(60 \%)$ & $6 / 41(15 \%)$ & $<0.001$ \\
\hline During admission & $7 / 45(16 \%)$ & $0 / 41(0 \%)$ & 0.01 \\
\hline After discharge & $20 / 38(53 \%)$ & $6 / 41(15 \%)$ & $<0.001$ \\
\hline Plasma viral load (mean \pm SD in $\log 10 / \mathrm{mL}$ ) & $6.02 \pm 1.08 n=13$ & $5.43 \pm 0.85 n=12$ & 0.15 \\
\hline Severe immunodeficient (based on CD4\%*) & $9 / 16(56 \%)$ & $5 / 12(42 \%)$ & 0.45 \\
\hline
\end{tabular}

Markers of disease progression in children with severe anaemia (cases $\mathrm{Hb}<5.0 \mathrm{~g} / \mathrm{dL}$ ) as compared to those without severe anaemia (controls). SD: Standard deviation; Viral loads were performed using a in-house methods as described in the method section. $* A c c o r d i n g$ to the revised WHO guidelines CD4 <25\% (6-12. months); <20\% (I2-35 months); <25\% (36-59 months) [40].

likely to have been admitted to hospital in the past, were more wasted, immunodeficient for age and had higher plasma viral loads. Though the latter two results were only tested in a subset of children, none of these differences reached significance (Table 2). During follow-up, HIVinfected children with severe anaemia had a significant increased mortality (53\%) compared to those without severe anaemia (15\%).

\section{Sample Processing}

Overall 29 (64\%) of HIV-infected cases and 30 (73\%) of HIV-infected controls had samples available for further analysis of the env fragment (Table 3). For one patient the PCR failed, resulting in a recovery rate of $98 \%$. For seven other samples the env fragment could only be partially amplified (V3 failed: $\mathrm{n}=5$ and C2 failed: $\mathrm{n}=2$ ). Cloning was needed to determine consensus sequences for 14 samples. In one sample V1-V2 fragment the nucleotide differences were too large between clones, two consensus sequences were made and separately analysed. However V3 loops of these clones were found to be identical. Degenerate base counts were taken into account and were not different between cases and controls $(\mathrm{p}=0.33$, Table 3).

\section{Phylogenetic analysis}

Phylogenetic analysis of V1-V2 nucleotide sequences showed that 57 of 58 isolates clustered with subtype $\mathrm{C}$ ref- erence sequences (bootstrap value: 99\%, Figure 2). Only one child, a child recruited as control, had a new circulating recombinant form that showed similarity with CRF13cpx, which has genomic regions identified as subtypes $A$, $\mathrm{G}$, and $\mathrm{J}[46]$.

\section{Amino acid charges $V$ fragments}

Amino-acid charges of the V3 loop and the total V1-V3 fragment are displayed in Figure 3 and 4 respectively. The charges of the subtype $\mathrm{C}$ isolates ranged from +2 to +5 (V3) and from 1 to +7 (V1-V3) and were not significantly different between the study groups $(\mathrm{p}=0.19$ and 0.36 respectively). Higher V3 charges ( +5 or more) were found in four isolates tested (7.7\%), all in controls (Table 3). Additional file 1 shows the amino acid logos for the V3 loop per study group. Alterations of the amino acid in positions, 5-9, 11 and 25 of the V3 loop were not different $(p>0.2$ for all).

\section{Potential N-linked glycosylation sites}

All isolates contained one potential N-linked glycosylation site in the V3 loop. The number of potential glycosylation sites on the V1-V3 fragment ranged between 10 and 17 (Figure 5) and was not different amongst cases and controls $(\mathrm{p}=0.75)$.

Table 3: Variability and predictors of co-receptor affinity per study group.

\begin{tabular}{|c|c|c|c|}
\hline & Cases & Controls & $\mathbf{p}$ \\
\hline Available for testing & $29 / 45(64 \%)$ & $30 / 4 I(73 \%)$ & 0.38 \\
\hline PCR failed & $0 / 29$ & $1 / 30$ & 1.00 \\
\hline Complete env product & $25 / 29$ & $26 / 29$ & 1.00 \\
\hline Degenerate base counts (median, range) & $2(0-2 I)$ & $4(0-36)$ & 0.33 \\
\hline Viral type C & $29 / 29$ & $28 / 29$ & 1.00 \\
\hline V3 amino acid charge $\geq+5^{*}$ & $0 / 25$ & $4 / 27$ & 0.11 \\
\hline X4 strains (C-PSSM)* & $2 / 25$ & $2 / 27$ & 1.00 \\
\hline
\end{tabular}

Presence of several indicators of co-receptor affinity in children with severe anaemia (cases, $\mathrm{Hb}<5.0 \mathrm{~g} / \mathrm{dL}$ ) as compared to those without severe anaemia (controls). * according to C-PSSM score by Jensen [25], available at [45]. 


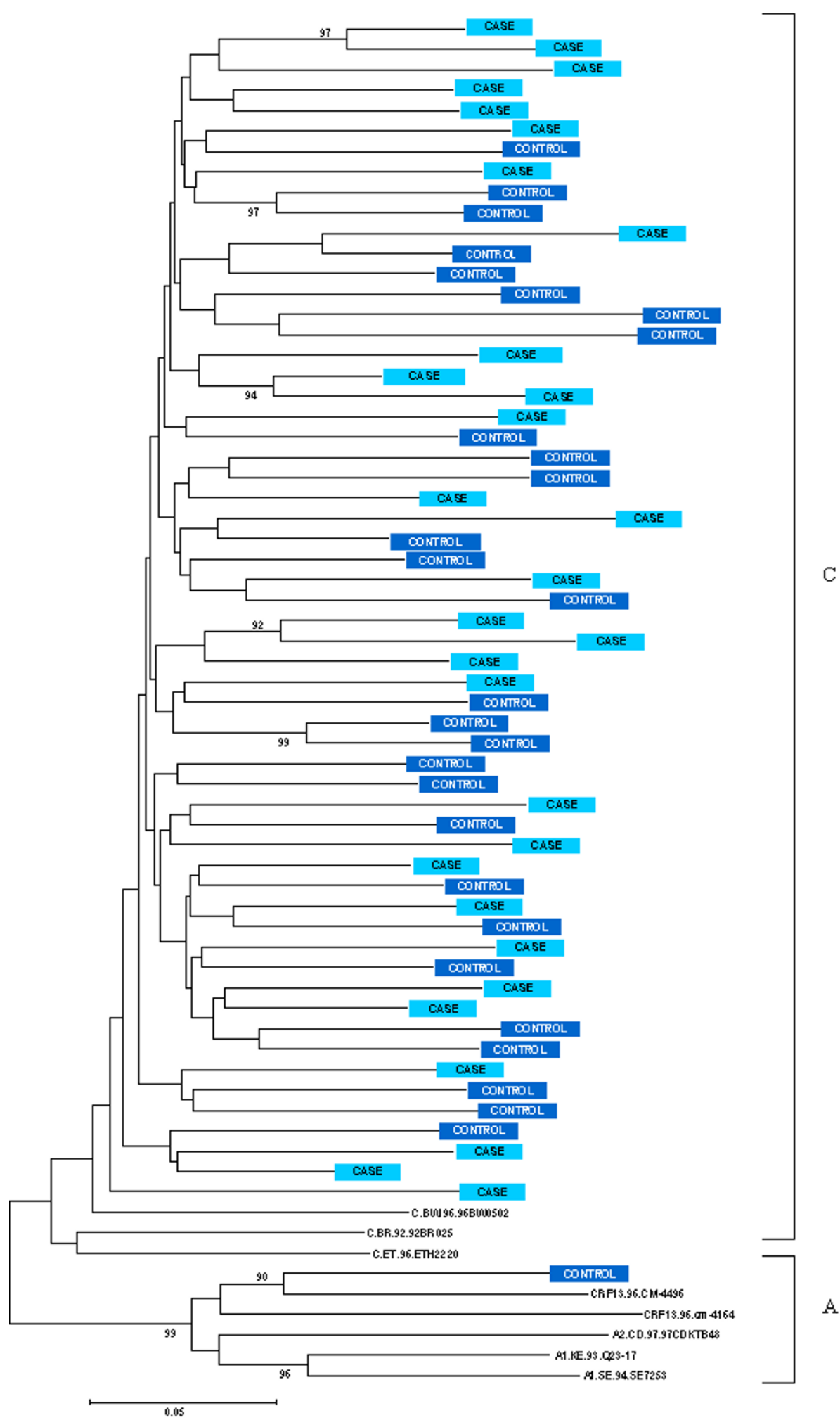

Figure 2

Phylogenetic tree based on the VI-V2 fragment of the HIV-I env gene nucleotide sequences. Phylogenetic tree to assess if the HIV-I genome of children with severe anaemia (cases, $\mathrm{Hb}<5.0 \mathrm{~g} / \mathrm{dL}$ ) is different from those without severe anaemia (controls). Subtype A and CRF-I 3 reference sequences are used as outgroup sequence. 


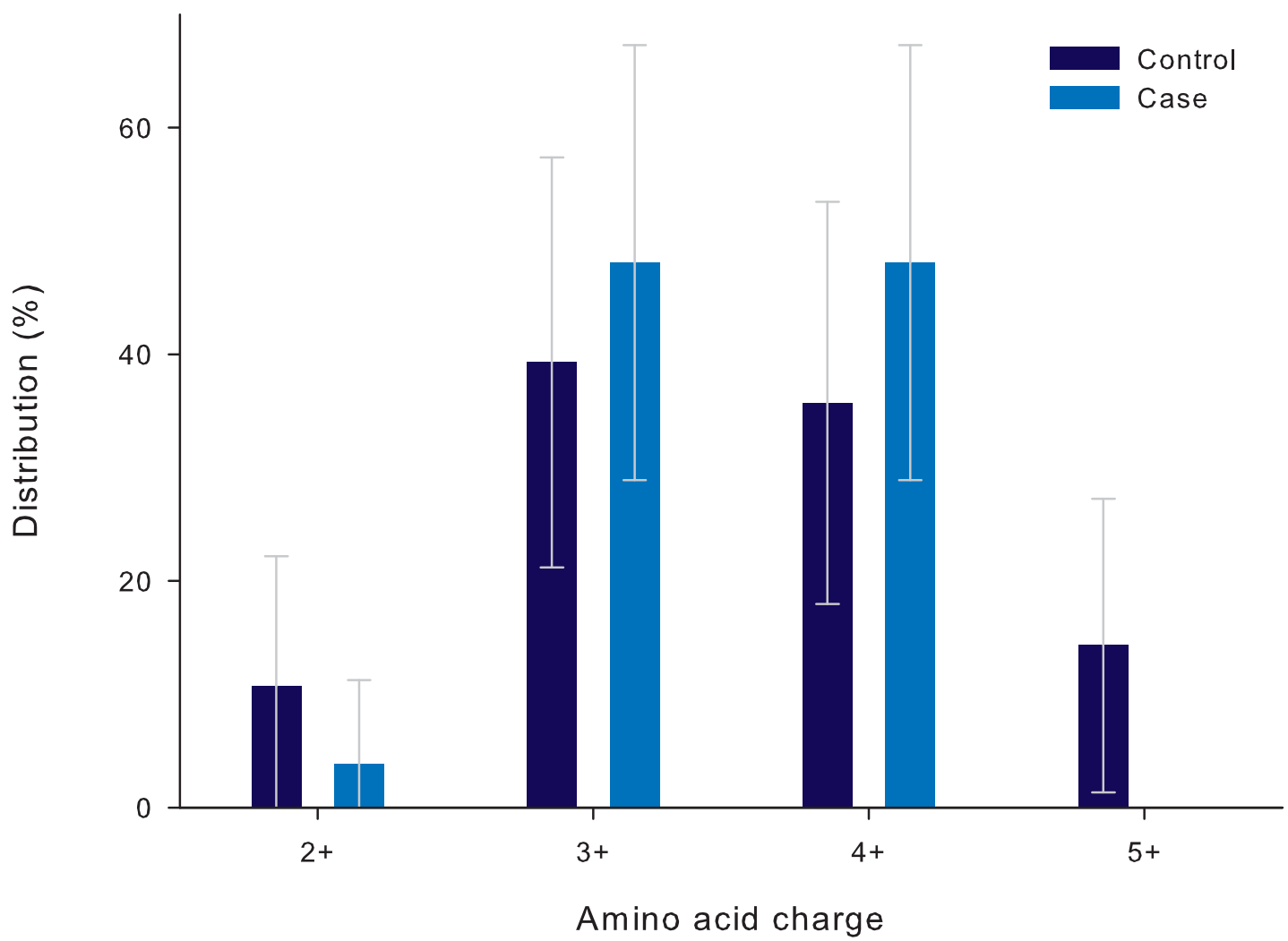

Figure 3

Distribution of V3 amino acid charges per study group. Distribution of the nett charges of the V3 fragment in children with severe anaemia (cases, $\mathrm{Hb}<5.0 \mathrm{~g} / \mathrm{dL}$ ) as compared to those without severe anaemia (controls). The distribution is expressed as a percentage of the total number of codons analysed per study group (Controls: $n=28$, Cases $n=26$ ). Error bars express $95 \%$ Confidence intervals. $p=0.19$.

\section{Length of the VI-V2 fragment}

The distribution of the length of the V1-V2 fragment ranged from 177 to 255 base pairs and is displayed in Figure 6. Mean length for cases was not significantly different from controls ( 214 vs. 211 base pairs respectively, $\mathrm{p}=$ $0.55)$.

\section{C-Position Specific Scoring Matrix}

C-PSSM scores were used to predict co-receptor affinity for HIV-1 subtype C strains using V3 loop data. Within our study X4 tropism was found in 2 of $25(8.0 \%)$ cases and 2 of 27 controls tested $(7.4 \%, \mathrm{p}=1.0$, Table 3$)$. Both CPSSM results for the child with two different clones suggested identical co-receptor affinity (CCR5). One of four children identified with an X4 strain according to this method had previously received a blood transfusion.

\section{Bone Marrow isolates}

Some studies have suggested different compartments of the body may contain different viral strains. For 15 cases bone marrow samples were available. Synonymous changes in the amino acid sequences of the V3 fragments between bone marrow and peripheral blood isolates were observed in three children (20\%). These patients showed alterations of amino acid structure at position $25(\mathrm{n}=2$, both $e->d)$, and $29(n=1, n->d)$, changes that did not effect the C-PSSM prediction.

\section{Follow-up}

After recruitment all children were followed during an 18 month follow-up period as part of this study. During this follow-up period none of the four children (two cases and two controls) that were infected with an R4 virus were diagnosed with a (new) episode of severe anaemia. The two cases died during follow up at 65 and 182 days from recruitment from other causes than severe anaemia. 


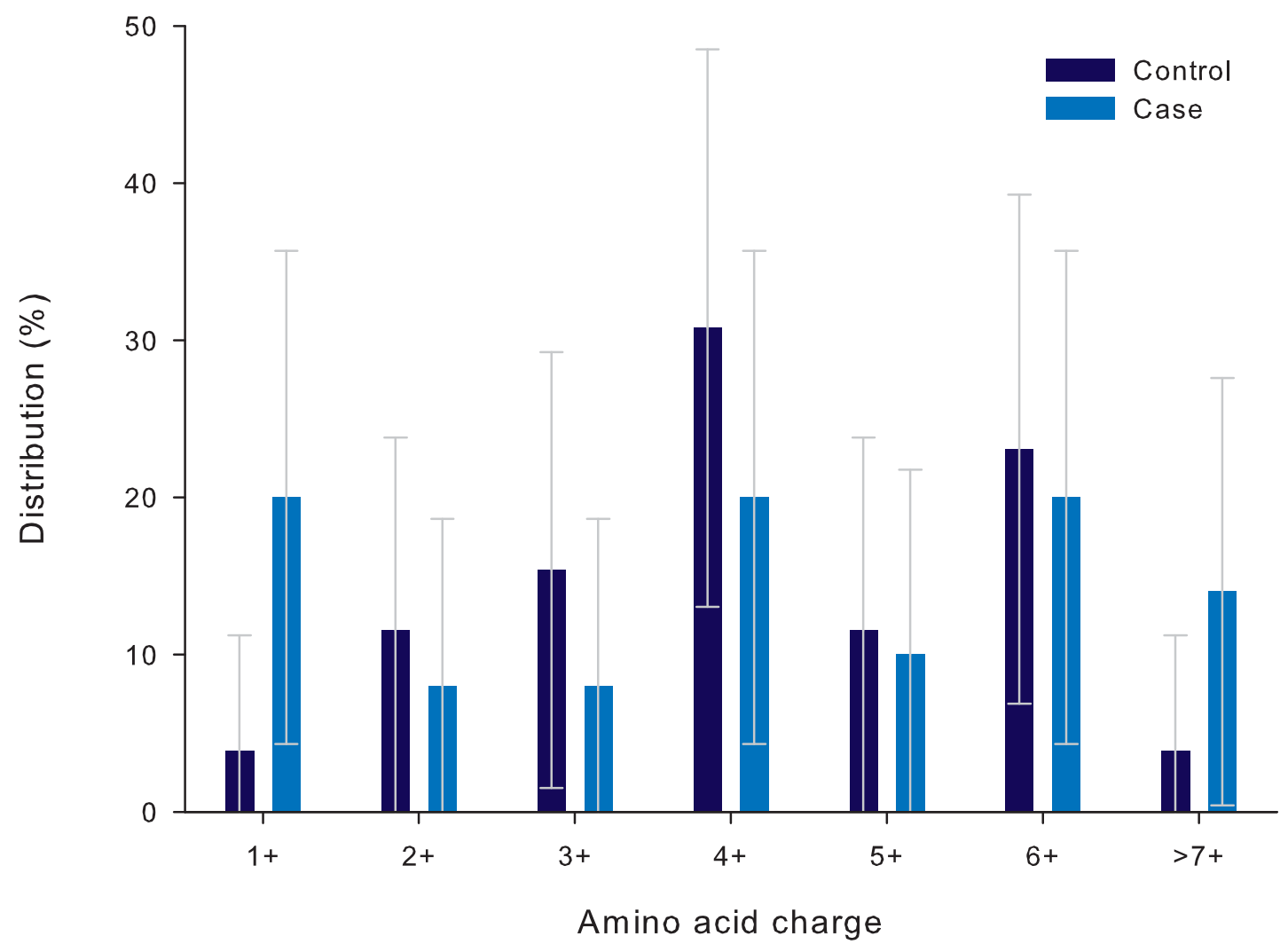

Figure 4

Distribution of total amino acid charge of the VI-V2-V3 fragment per study group. Distribution of the nett charges of the VI-V2-V3 fragment in children with severe anaemia (cases, $\mathrm{Hb}<5.0 \mathrm{~g} / \mathrm{dL}$ ) as compared to those without severe anaemia (controls). The distribution is expressed as a percentage of the total number of fragments analysed per study group (Controls: $n=26$, Cases $n=25$ ). Error bars express $95 \%$ Confidence intervals. $p=0.36$.

\section{Discussion}

Severe anaemia is major cause of morbidity and mortality in African children [47]. We previously reported that in an urban environment as many as $21 \%$ of children admitted with severe anaemia were HIV-infected which was more than twice as prevalent as for the control population. This association could only partly be explained by more prevalent secondary infections and an additional modest contribution of nutrient deficiencies. A direct effect of HIV on erythropoiesis was suspected and we assessed if HIV-1 envelope characteristics and co-receptor affinity were associated with the occurrence of severe anaemia in these children. In this first study to assess this association using a case-control design, we found no variations in the genetic domain of HIV env or the predicted prevalence of $\mathrm{X} 4$ strains between children with and without severe anaemia.

HIV-1 subtype C appeared to be the most prevalent subtype in our sample. Previous reports on adults and children in the region have confirmed that in Malawi HIV-1 subtype $C$ is the most prevalent variant $[48,49]$. A new recombinant form was identified in one of the control children and showed similarities to CRF13-cpx, recently found in Cameroon [50]. Since this strain is very different from all other isolates found in Malawi, it might have spread from Central Africa by the major transports route running through the rural area in which this was found.

The phylogenetic tree based on the data from the env protein did not show clustering of cases as compared to controls and argues against our hypothesis that specific strains of HIV would predispose to the development of severe anaemia. More specifically we assessed V3 amino acid charge, overall V1-V2-V3 fragment charge, potential $\mathrm{N}$-linked glycosylation sites on the V1-V2-V3 and the V3 fragments, and V1-V2 length and did not identify any significant difference between HIV-infected children with and without severe anaemia.

Although much has been published on co-receptor affinity for HIV-1 subtype B, the strain commonly found in 


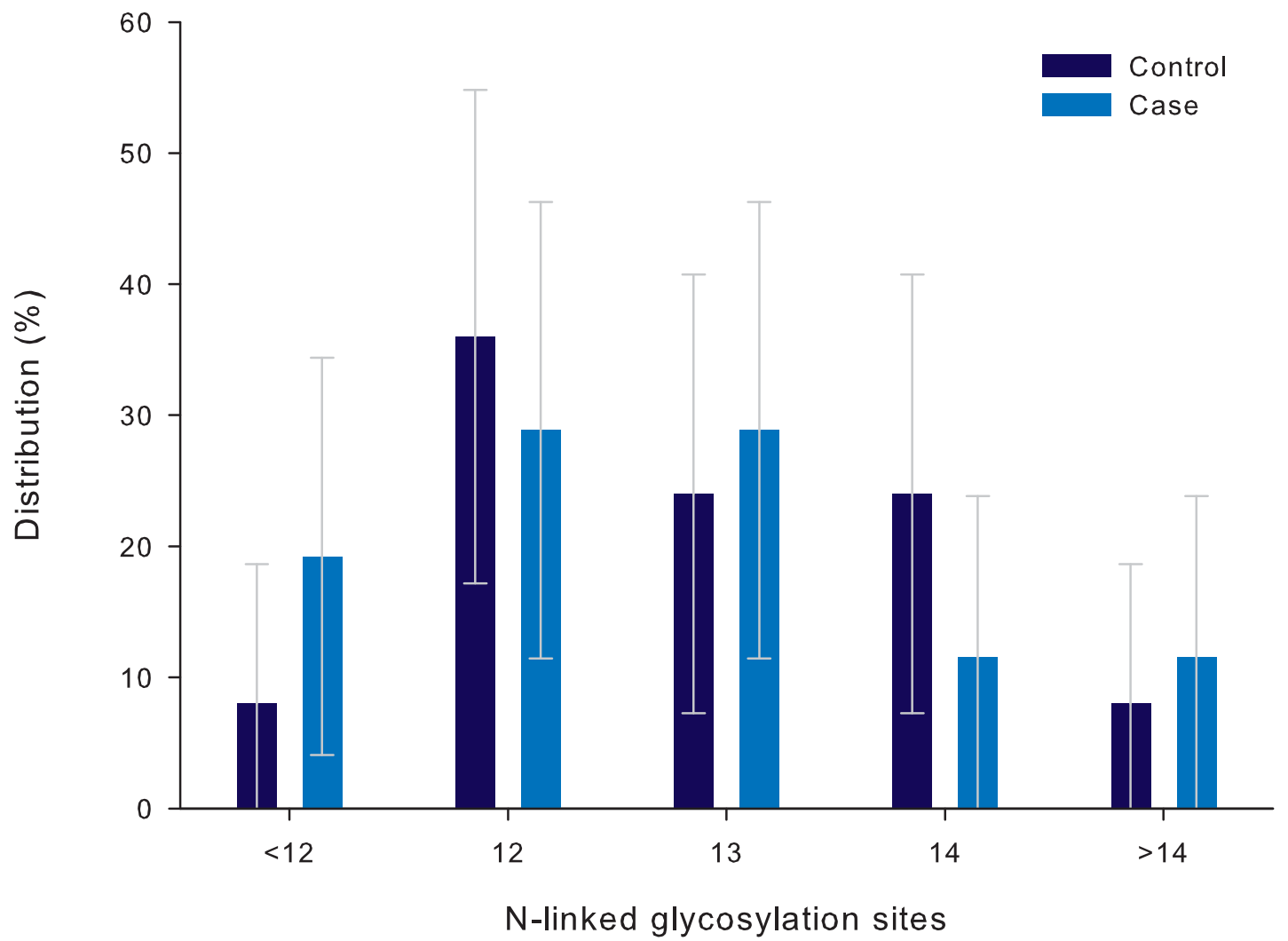

\section{Figure 5}

Distribution of potential $\mathbf{N}$-linked glycosylation sites on VI-V2-V3 per study group. Distribution of number of potential N-linked glycosylation sites on the VI-V2-V3 fragment in children with severe anaemia (cases, $\mathrm{Hb}<5.0 \mathrm{~g} / \mathrm{dL}$ ) as compared to those without severe anaemia (controls). The distribution is expressed as a percentage of the total number of fragments analysed per study group (Controls: $n=25$, Cases $n=26$ ). Error bars express $95 \%$. $p=0.75$.

western settings, relatively little is known on HIV-1 subtype $\mathrm{C}$ and co-receptor affiliation. Recently Jensen et al. published a validated algorithm to predict co-receptor usage in subtype C [25]. This C-PSSM score predicted X4 affinity in four strains, two in each study group.

The X4-strain prevalence of $7.7 \%$ in the case and control groups combined was higher than expected in this predominantly HIV-1 subtype C infected population $[20,48,51,52]$. Both studies reporting on co-receptor usage in Malawian populations did not identify a single X4-strain in both an adult [52] and paediatric [48] population. Others have published higher prevalences of X4strains in HIV-1 subtype C-infected patients, however these reports came from Zimbabwe and South Africa and concerned adults in end-stage HIV infection (17-36\%) $[20,51]$. Furthermore, this prevalence is remarkable since most children will have been vertically infected which is commonly considered to occur by R5 variants [9]. Previous studies have suggested that the occurrence of $\mathrm{X} 4$ strains in subtype $\mathrm{C}$ infections was associated with the use of anti-retroviral therapy (ART) [51]. No child was receiving ART at the time of this study.

The link between the occurrence of an X4 strain and disease progression is well studied in HIV-1 subtype Binfected persons. Little data is available concerning this association in HIV-1 subtype C-infected individuals. Our results suggest $\mathrm{X} 4$ variants are not uncommon in a HIV-1 subtype C-infected population and their survival, especially in the presence of anaemia, may be limited. Therefore more attention should be given to the clinical importance of the occurrence of this variant in HIV-1 subtype $\mathrm{C}$ infected children and adults.

A limitation of our study is that we used indirect measures to define co-receptor affinity rather than to assess actual infectivity of cell-lined expressing CXCR4 or CCR5. Since the C-PSSM method applied had a 94\% specificity and $75 \%$ sensitivity [25], we might have underestimated X4 


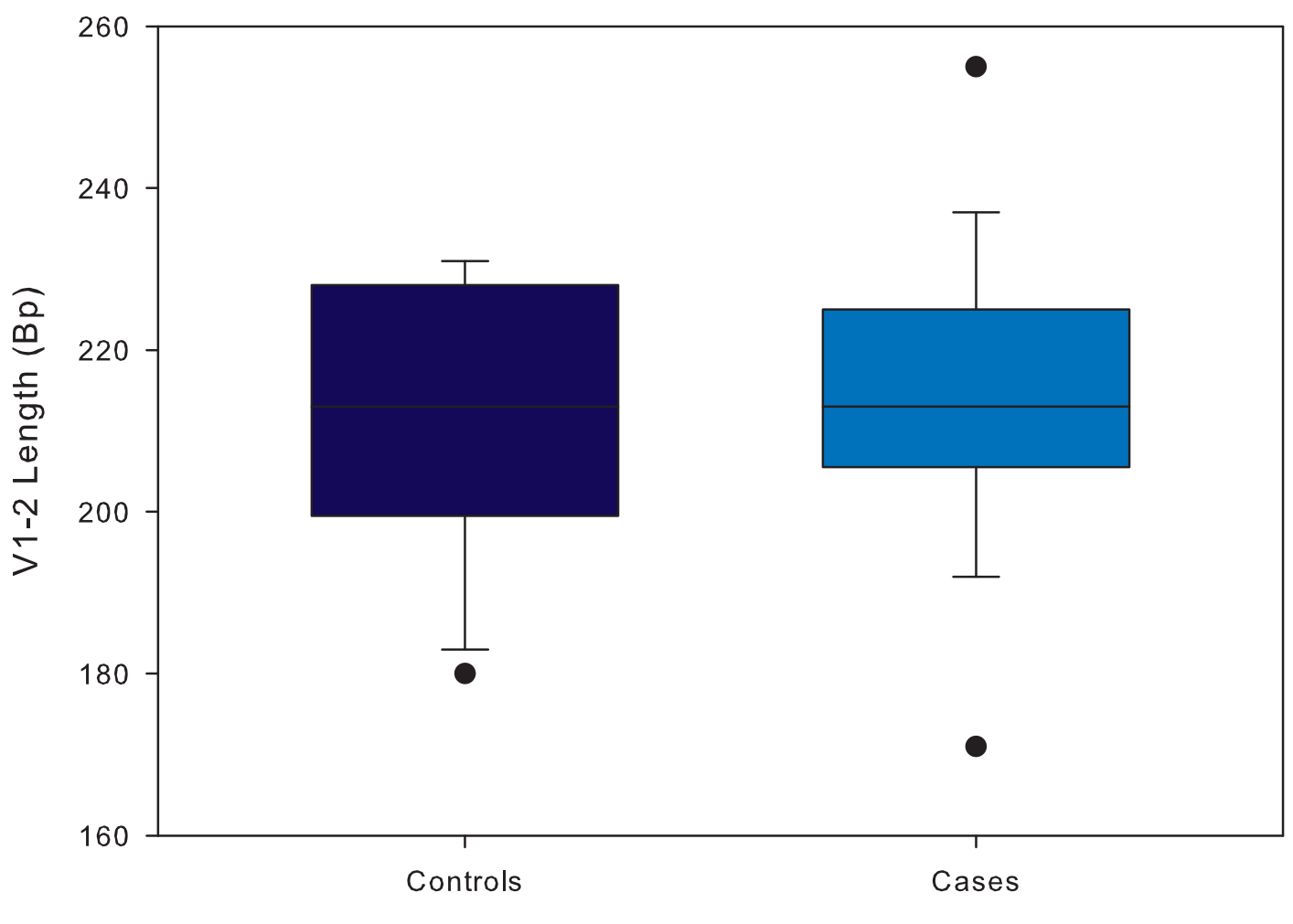

Studygroup

\section{Figure 6}

Boxplots of VI-V2 length per study group. Distribution of number of length of the VI-V2 fragment in children with severe anaemia (cases, $\mathrm{Hb}<5.0 \mathrm{~g} / \mathrm{dL}$ ) as compared to those without severe anaemia (controls). The length is expressed as in basepairs (bp). The analysis included 29 controls and 29 cases. Error bars express $95 \%$ confidence intervals, outliers are presented by dots. $p=0.55$

tropism in our entire population. Since this underestimation would have affected both our cases and controls it is unlikely to have had a major impact effect on our findings. We therefore did not pursue assessing our hypothesis using the more costly and laborious exercise of infecting cell lines expressing CXCR4 and CCR5. Although our data cannot fully refute an association between $\mathrm{X} 4$ strains and severe anaemia, X4 tropism is not a major cause of severe anaemia.

The study had several strengths including the case-control design and the long term follow-up period. This allowed a cross-sectional analysis of X4 infected children with a longitudinal assessment. We hypothesized that the occurrence of an X4 strain would predispose to severe anaemia. The cross-sectional design used may have been underpowered to detect a difference finding only four X4-infected children. However none of these four children developed a new episode of severe anaemia in the longitudinal study. This may be considered additional evidence against our hypothesis. Another strong point of the study was the availability of bone marrow samples in a subgroup of patients. The similarity of these isolates to those obtained from the peripheral blood argues against compartmentalisation in the bone marrow and strengthens our findings.

\section{Conclusion}

In summary, we assessed whether HIV-1 env characteristics and CXCR4 co-receptor affinity were associated with the occurrence of severe anaemia in Malawian children. In this first study assessing clinical relevance we were unable to find any differences either by phylogenetic analysis and several tests used to assess co-receptor usage. We identified a relatively high prevalence of X4 strains in these HIV1 subtype C-infected children that were young, most likely vertically infected and naïve to anti-retroviral therapy. More attention should be given to the clinical importance of the occurrence of this variant in HIV-1 subtype $\mathrm{C}$ infected children and adults. 


\section{Competing interests}

The author(s) declare that they have no competing interests.

\section{Authors' contributions}

JC conceived the study, was responsible for the on site laboratory work, statistical analysis and drafted the manuscript. HPR carried out the PCR and sequence analysis, and helped to draft the manuscript. DK was responsible for design and performance of the on site laboratory tests and reviewed the manuscript. $\mathrm{MBvH}$ helped conceiving the study and drafting the manuscript. ACvdK, FZ and MC participated in the design and coordination of the study and contributed to the laboratory work. All authors read and approved the final manuscript.

\section{Additional material}

\section{Additional file 1}

Frequency amino acid codon logos of the V3 loop per study group. Sequence logos of HIV-1 V3 sequences found in children with severe anaemia (cases, $H b<5.0 \mathrm{~g} / \mathrm{dL}, n=25$ ) as compared to those without severe anaemia (controls $n=28$ ). The character and size of each logo represent the amino acid and its prevalence at the specific site.

Click here for file

[http://www.biomedcentral.com/content/supplementary/14712334-8-26-S1.eps]

\section{Acknowledgements}

Funded the Wellcome Trust and the University of Amsterdam, supported by independent grants of the Nutricia Research Foundation and Ter Meulen Fund, Royal Academy of Arts and Sciences.

We thank the parents and guardians of the children admitted to the study, the SEVANA study team, the staff of the Queen Elizabeth Central Hospital, Chikwawa District Hospital, Wellcome Trust Research Laboratories and the departments of experimental and clinical virology of the Amsterdam Medical Centre and in particular SM Graham, EM Molyneux, RJWM Vet, A Zelleke, MGHM Beld, S Jurriaans, JJE Brouwer, G Pollakis, WA Paxton and $R$ de Haan for their contribution to the study.

\section{References}

I. Zon LI, Arkin C, Groopman JE: Haematologic manifestations of the human immune deficiency virus (HIV). BrJ Haematol I987, 66:25I-256.

2. Ellaurie M, Burns ER, Rubinstein A: Hematologic manifestations in pediatric HIV infection: severe anemia as a prognostic factor. Am J Pediatr Hematol Oncol 1990, 12:449-453.

3. Moses A, Nelson J, Bagby GC Jr: The influence of human immunodeficiency virus-I on hematopoiesis. Blood 1998, 91:1479-1495.

4. Bain BJ: The haematological features of HIV infection. BrJ Haematol 1997, 99: I-8.

5. Moore RD, Keruly JC, Chaisson RE: Anemia and survival in HIV infection. J Acquir Immune Defic Syndr Hum Retrovirol 1998, 19:29-33.

6. Bain BJ: Pathogenesis and pathophysiology of anemia in HIV infection. Curr Opin Hematol 1999, 6:89-93.

7. Gibellini D, Re MC, Vitone F, Rizzo N, Maldini C, La PM, et al.: Selective up-regulation of functional CXCR4 expression in eryth- roid cells by HIV-I Tat protein. Clin Exp Immunol 2003, 131:428-435.

8. Zauli G, Vitale M, Re MC, Furlini G, Zamai L, Falcieri E, et al:: In vitro exposure to human immunodeficiency virus type $I$ induces apoptotic cell death of the factor-dependent TF-I hematopoietic cell line. Blood 1994, 83:167-175.

9. Casper CH, Clevestig P, Carlenor E, Leitner T, Anzen B, Lidman K, et al: Link between the $X 4$ phenotype in human immunodeficiency virus type I-infected mothers and their children, despite the early presence of $\mathbf{R 5}$ in the child. J Infect Dis 2002, 186:914-921.

10. Connor RI, Sheridan KE, Ceradini D, Choe S, Landau NR: Change in coreceptor use coreceptor use correlates with disease progression in HIV-I - infected individuals. J Exp Med 1997, 185:62I-628.

II. Scarlatti G, Tresoldi E, Bjorndal A, Fredriksson R, Colognesi C, Deng $\mathrm{HK}$, et al.: In vivo evolution of HIV-I co-receptor usage and sensitivity to chemokine-mediated suppression. Nat Med 1997, 3:1259-1265.

12. Tersmette M, Lange JM, de Goede RE, de WF, Eeftink-Schattenkerk JK, Schellekens PT, et al:: Association between biological properties of human immunodeficiency virus variants and risk for AIDS and AIDS mortality. Lancet 1989, I:983-985.

13. Majka M, Ratajczak J, Lee B, Honczarenko M, Douglas R, Kowalska $M A$, et al.: The role of HIV-related chemokine receptors and chemokines in human erythropoiesis in vitro. Stem Cells 2000, 18:128-138.

14. Aiuti A, Turchetto L, Cota M, Cipponi A, Brambilla A, Arcelloni C, et al.: Human CD34(+) cells express CXCR4 and its ligand stromal cell-derived factor- I. Implications for infection by T-cell tropic human immunodeficiency virus. Blood 1999, 94:62-73.

15. Voulgaropoulou F, Pontow SE, Ratner L: Productive infection of CD34+-cell-derived megakaryocytes by $X 4$ and R5 HIV-I isolates. Virology 2000, 269:78-85.

16. Rozmyslowicz T, Majka M, Kijowski J, Murphy SL, Conover DO, Poncz $M$, et al: Platelet- and megakaryocyte-derived microparticles transfer CXCR4 receptor to CXCR4-null cells and make them susceptible to infection by X4-HIV. AIDS 2003, 17:33-42.

17. Vlahakis SR, geciras-Schimnich A, Bou G, Heppelmann CJ, VillasisKeever A, Collman RC, et al: Chemokine-receptor activation by env determines the mechanism of death in HIV-infected and uninfected T lymphocytes. J Clin Invest 200I, 107:207-2I5.

18. Mocroft A, Kirk O, Barton SE, Dietrich M, Proenca R, Colebunders $R$, et al: Anaemia is an independent predictive marker for clinical prognosis in HIV-infected patients from across Europe. EuroSIDA study group. AIDS 1999, I 3:943-950.

19. Sullivan PS, Hanson DL, Chu SY, Jones JL, Ward JW: Epidemiology of anemia in human immunodeficiency virus (HIV)-infected persons: results from the multistate adult and adolescent spectrum of HIV disease surveillance project. Blood 1998, $91: 301-308$

20. Cilliers T, Nhlapo J, Coetzer M, Orlovic D, Ketas T, Olson WC, et al: The CCR5 and CXCR4 coreceptors are both used by human immunodeficiency virus type I primary isolates from subtype C. I Virol 2003, 77:4449-4456.

21. De Jong JJ, De RA, Keulen W, Tersmette M, Goudsmit J: Minimal requirements for the human immunodeficiency virus type $I$ V3 domain to support the syncytium-inducing phenotype: analysis by single amino acid substitution. I Virol 1992, 66:6777-6780.

22. Fouchier RA, Groenink M, Kootstra NA, Tersmette M, Huisman HG, Miedema $F$, et al:: Phenotype-associated sequence variation in the third variable domain of the human immunodeficiency virus type I gp I 20 molecule. J Virol 1992, 66:3 I83-3I87.

23. Fouchier RA, Brouwer M, Broersen SM, Schuitemaker H: Simple determination of human immunodeficiency virus type I syncytium-inducing V3 genotype by PCR. J Clin Microbiol 1995, 33:906-911.

24. Hartley O, Klasse PJ, Sattentau QJ, Moore JP: V3: HIV's switch-hitter. AIDS Res Hum Retroviruses 2005, 2 1: I7I-189.

25. Jensen MA, Coetzer M, van 't Wout AB, Morris L, Mullins JI: A reliable phenotype predictor for human immunodeficiency virus type I subtype $C$ based on envelope V 3 sequences. J Virol 2006, 80:4698-4704. 
26. Jensen MA, Li FS, van 't Wout AB, Nickle DC, Shriner D, He HX, et al.: Improved coreceptor usage prediction and genotypic monitoring of R5-to-X4 transition by motif analysis of human immunodeficiency virus type I env V3 loop sequences. J Virol 2003, 77:13376-13388.

27. Jensen MA, van ' $t$ Wout AB: Predicting HIV-I coreceptor usage with sequence analysis. AIDS Rev 2003, 5:104-II2.

28. Resch W, Hoffman N, Swanstrom R: Improved success of phenotype prediction of the human immunodeficiency virus type I from envelope variable loop 3 sequence using neural networks 2. Virology 200I, 288:5I-62.

29. Coetzer M, Cilliers T, Papathanasopoulos M, Ramjee G, Karim SA, Williamson C, et al.: Longitudinal Analysis of HIV Type I Subtype C Envelope Sequences from South Africa. AIDS Res Hum Retroviruses 2007, 23:316-321.

30. Pollakis G, Kang S, Kliphuis A, Chalaby MI, Goudsmit J, Paxton WA: $\mathbf{N}$-linked glycosylation of the HIV type-I gpI20 envelope glycoprotein as a major determinant of CCR5 and CXCR4 coreceptor utilization. J Biol Chem 200I, 276: I3433-I344I.

31. Pollakis G, Abebe A, Kliphuis A, Chalaby MI, Bakker M, Mengistu Y, et al.: Phenotypic and genotypic comparisons of CCR5- and CXCR4-tropic human immunodeficiency virus type I biological clones isolated from subtype $\mathbf{C}$-infected individuals. J Virol 2004, 78:284I-2852

32. Cao J, Sullivan N, Desjardin E, Parolin C, Robinson J, Wyatt R, et al.: Replication and neutralization of human immunodeficiency virus type I lacking the VI and V2 variable loops of the gp I 20 envelope glycoprotein. J Virol 1997, 71:9808-9812.

33. Pinter A, Honnen WJ, He Y, Gorny MK, Zolla-Pazner S, Kayman SC: The VI/V2 domain of gp I 20 is a global regulator of the sensitivity of primary human immunodeficiency virus type I isolates to neutralization by antibodies commonly induced upon infection. J Virol 2004, 78:5205-52I5.

34. Sagar $M, W u X$, Lee $S$, Overbaugh J: Human immunodeficiency virus type I VI-V2 envelope loop sequences expand and add glycosylation sites over the course of infection, and these modifications affect antibody neutralization sensitivity. J Virol 2006, 80:9586-9598.

35. Wei X, Decker JM, Wang S, Hui H, Kappes JC, Wu X, et al:: Antibody neutralization and escape by HIV-I. Nature 2003 422:307-3। 2 .

36. Groenink M, Fouchier RA, Broersen S, Baker $\mathrm{CH}$, Koot $\mathrm{M}$, van't Wout $A B$, et al: Relation of phenotype evolution of HIV-I to envelope V2 configuration. Science 1993, 260:I5I3-I5I6.

37. Jansson M, Backstrom E, Scarlatti G, Bjorndal A, Matsuda S, Rossi P, et al.: Length variation of glycoprotein $120 \mathrm{~V} 2$ region in relation to biological phenotypes and coreceptor usage of primary HIV type I isolates. AIDS Res Hum Retroviruses 200I, I 7:|405-|4|4.

38. Calis JCJ, Phiri KS, Faragher EB, Brabin BJ, Bates I, Cuevas LE, et al.: Factors associated with severe anemia in Malawian children. N Engl J Med 2007 in press.

39. Dibley MJ, Goldsby JB, Staehling NW, Trowbridge FL: Development of normalized curves for the international growth reference: historical and technical considerations. Am J Clin Nutr 1987 , 46:736-748.

40. WHO: WHO case definitions of HIV for surveillance and revised clinical staging and immunological classification of HIV-related disease in adults and children. Geneva, World Health Organization; 2006. 19-I-0007. Ref Type: Internet Communication

4I. Boom R, Sol C, Beld M, Weel J, Goudsmit J, Wertheim-van DP: Improved silica-guanidiniumthiocyanate DNA isolation procedure based on selective binding of bovine alpha-casein to silica particles. J Clin Microbiol 1999, 37:615-619.

42. Thompson JD, Higgins DG, Gibson TJ: CLUSTAL W: improving the sensitivity of progressive multiple sequence alignment through sequence weighting, position-specific gap penalties and weight matrix choice. Nucleic Acids Res 1994, 22:4673-4680.

43. The Los Alamos HIV sequence database 2007 [http:// www.hiv.lanl.gov].

44. Kasturi L, Eshleman JR, Wunner WH, Shakin-Eshleman SH: The hydroxy amino acid in an Asn-X-Ser/Thr sequon can influence $\mathbf{N}$-linked core glycosylation efficiency and the level of expression of a cell surface glycoprotein. I Biol Chem 1995, 270:|4756-|476|.
45. Online C-PSSM predictor by MA Jenssen 2007 http://mull inslab.microbiol.washington.edu/computing/pssm]. Ref Type: Electronic Citation

46. Wilbe K, Casper C, Albert J, Leitner T: Identification of two CRF I I-cpx genomes and two preliminary representatives of a new circulating recombinant form (CRFI3-cpx) of HIV type I in Cameroon. AIDS Res Hum Retroviruses 2002, I 8:849-856.

47. Brabin BJ, Premji Z, Verhoeff F: An analysis of anemia and child mortality. J Nutr 200I, I 3 I:636S-645S

48. Biggar RJ, Janes M, Pilon R, Roy R, Broadhead R, Kumwenda N, et al.: Human immunodeficiency virus type $I$ infection in twin pairs infected at birth. I Infect Dis 2002, 186:28I-285.

49. Travers SA, Clewley JP, Glynn JR, Fine PE, Crampin AC, Sibande F, et al.: Timing and reconstruction of the most recent common ancestor of the subtype $\mathbf{C}$ clade of human immunodeficiency virus type I. J Virol 2004, 78:1050 I-10506.

50. Wilbe K, Casper C, Albert J, Leitner T: Identification of two CRFI I-cpx genomes and two preliminary representatives of a new circulating recombinant form (CRFI3-cpx) of HIV type I in Cameroon. AIDS Res Hum Retroviruses 2002, I 8:849-856.

5I. Johnston ER, Zijenah LS, Mutetwa S, Kantor R, Kittinunvorakoon C, Katzenstein DA: High frequency of syncytium-inducing and CXCR4-tropic viruses among human immunodeficiency virus type I subtype $C$-infected patients receiving antiretroviral treatment. J Virol 2003, 77:7682-7688.

52. Ping LH, Nelson JA, Hoffman IF, Schock J, Lamers SL, Goodman M, et al.: Characterization of $\mathrm{V} 3$ sequence heterogeneity in subtype $\mathbf{C}$ human immunodeficiency virus type $\mathbf{I}$ isolates from Malawi: underrepresentation of X4 variants. J Virol 1999 , 73:627|-628I.

\section{Pre-publication history}

The pre-publication history for this paper can be accessed here:

http://www.biomedcentral.com/1471-2334/8/26/prepub
Publish with Biomed Central and every scientist can read your work free of charge

"BioMed Central will be the most significant development for disseminating the results of biomedical research in our lifetime. "

Sir Paul Nurse, Cancer Research UK

Your research papers will be:

- available free of charge to the entire biomedical community

- peer reviewed and published immediately upon acceptance

- cited in PubMed and archived on PubMed Central

- yours - you keep the copyright
BioMedcentral 